\title{
Corticotropin-Releasing Factor Receptor 1 Antagonist Alters Regional Activation and Effective Connectivity in an Emotional-Arousal Circuit during Expectation of Abdominal Pain
}

\author{
Catherine S. Hubbard, ${ }^{1,2}$ Jennifer S. Labus, ${ }^{1,4}$ Joshua Bueller, ${ }^{1,2}$ Jean Stains, ${ }^{1,2}$ Brandall Suyenobu, ${ }^{1,2}$ George E. Dukes, ${ }^{6}$ \\ Dennis L. Kelleher, ${ }^{6}$ Kirsten Tillisch, ${ }^{1,2}$ Bruce D. Naliboff, ${ }^{1,4,5}$ and Emeran A. Mayer ${ }^{1,2,3,4}$ \\ ${ }^{1}$ Center for the Neurobiology of Stress and Departments of ${ }^{2}$ Medicine, ${ }^{3}$ Physiology, and ${ }^{4}$ Psychiatry, University of California, Los Angeles, Los Angeles, \\ California 90095, ${ }^{5}$ Veterans Administration Greater Los Angeles Healthcare System, Los Angeles, California 90073, and ${ }^{6} \mathrm{GlaxoSmithKline,} \mathrm{Research}$ \\ Triangle Park, North Carolina 27709
}

\begin{abstract}
Alterations in corticotropin-releasing factor (CRF) signaling pathways have been implicated in irritable bowel syndrome (IBS) pathophysiology. We aimed to (1) determine the effect of the selective CRF receptor 1 antagonist $\left(\mathrm{CRF}_{1}\right) \mathrm{GW876008}$ relative to placebo, on regional activation and effective connectivity of a stress-related emotional-arousal circuit during expectation of abdominal pain using functional magnetic resonance imaging in human subjects with a diagnosis of IBS and healthy controls (HCs), and (2) examine GW876008 effects on state-trait anxiety and hypothalamic-pituitary-adrenal (HPA) axis response. Although there were no drug-related effects on peripheral HPA activity, significant central effects were observed in brain regions associated with the stress response. Effective connectivity analysis showed drug-induced normalizations between key regions of the emotional-arousal circuit in patients. During pain expectation, orally administered GW876008 relative to placebo produced significant blood oxygen level-dependent (BOLD) signal reductions in the amygdala, hippocampus, insula, anterior cingulate, and orbitomedial prefrontal cortices across groups. Patients showed significantly greater BOLD responses in the left locus coeruleus and hypothalamus after placebo compared with HCs, and BOLD signal decreases in the left hypothalamus after drug. The inhibitory effects of GW876008 in the hypothalamus in patients were moderated by anxiety; patients having average and high levels of state anxiety showed drug-related BOLD decreases. GW876008 represents a novel tool for elucidating the neuronal mechanisms and circuitry underlying hyperactivation of $\mathrm{CRF}_{\mathrm{CRF}}$ signaling and its role in IBS pathophysiology. The unique state anxiety effects observed suggest a potential pathway for therapeutic benefit of $\mathrm{CRF}_{1}$ receptor antagonism for patients with stress-sensitive disorders.
\end{abstract}

\section{Introduction}

Corticotropin-releasing factor (CRF) is considered the principal regulator of the vertebrate stress response. In addition to its role in the activation of the hypothalamic-pituitary-adrenal (HPA) axis (Vale et al., 1981), CRF targets extrahypothalamic sites to mediate behavioral, autonomic, and neurochemical responses to stress (Dunn and Berridge, 1990). Alterations of this complex system in humans have been linked to a variety of anxiety-related

Received April 13, 2011; revised June 22, 2011; accepted July 6, 2011.

Author contributions: G.E.D., D.L.K., K.T., B.D.N., and E.A.M. designed research; J.B., J.S., B.S., and K.T. performed research; C.S.H., J.S.L., J.B., and B.S. analyzed data; C.S.H., J.S.L., J.B., B.D.N., and E.A.M. wrote the paper.

This research was supported by GlaxoSmithKline, NIH Grants R01 DK 48351, P50 DK 64539, R24 AT002681, K23 DK 073451-05, and K08 DK 071626, and NIH GI Training Grant T32-DK07180-34. We thank Dr. Yvette Taché for valuable comments to this manuscript.

E.A.M. has been an advisory board member for GlaxoSmithKline, and G.E.D. and D.L.K. are GlaxoSmithKline employees.

Correspondence should be addressed to Dr. Emeran A. Mayer, Center for Neurobiology of Stress, Division of Digestive Diseases, University of California, Los Angeles, CHS 47-122, 10833 Le Conte Avenue, Los Angeles, CA 90095-7378. E-mail: emayer@ucla.edu.

DOI:10.1523/JNEUROSCI.1860-11.2011

Copyright $\odot 2011$ the authors $\quad 0270-6474 / 11 / 3112491-10 \$ 15.00 / 0$ psychiatric disorders and stress-sensitive pain syndromes, including irritable bowel syndrome (IBS) (Arborelius et al., 1999; Fukudo, 2007).

IBS is a common gastrointestinal disorder, characterized by chronic abdominal pain, altered bowel habits, increased anxiety, and stress sensitivity of symptoms (Mayer, 2000; Longstreth et al., 2006). Although IBS pathophysiology remains incompletely understood, extensive preclinical and some clinical evidence suggests increased engagement of the CRF/CRF receptor $1\left(\mathrm{CRF}_{1}\right)$ signaling system (Martinez and Taché, 2006). In rodents, stressinduced release or exogenously administered CRF increases anxiety-like behaviors and stimulates colonic secretion, intestinal motility, and visceral sensitivity (Taché et al., 2009). Deletion of the $\mathrm{CRF}_{1}$ gene using transgenic models or intraventricular administered $\mathrm{CRF}_{1}$ antagonists have anxiolytic affects and attenuate stress- and CRF-induced alterations in gastric and colonic motor function (Million et al., 2003; Trimble et al., 2007). Moreover, recent clinical investigations have shown that intravenously administered CRF increases gastrointestinal motility and visceral pain sensitivity in IBS patients compared with healthy controls 
(HCs), whereas administration of a nonselective CRF receptor antagonist ameliorated these responses (Lembo et al., 1996; Fukudo et al., 1998; Sagami et al., 2004). Together, these findings have spurred the development of novel and highly selective $\mathrm{CRF}_{1}$ antagonists as candidate drugs for treatment of IBS (Zorrilla and Koob, 2010).

Functional magnetic resonance imaging (fMRI) is ideally suited as a non-invasive tool for investigating the modulatory effects of CRF/CRF 1 signaling on stress-related emotional-arousal circuits in humans, most notable of which include the amygdala (AMYG), hippocampus (HPC), hypothalamus (HT), locus coeruleus complex (LCC), and insular (INS), anterior cingulate (ACC), and orbitomedial prefrontal (OFC) cortices (Valentino et al., 1999; Pezawas et al., 2005; Stein et al., 2007; Labus et al., 2008). The well-established functional neuroanatomy of stress-related emotional-arousal circuits gleaned from neuroimaging studies, combined with the known distribution of $\mathrm{CRF}_{1}$ and CRFexpressing neurons in rodent and nonhuman primate brains (Aguilera et al., 1987; Dunn and Berridge, 1990), allow for specific hypothesis-driven study designs to investigate the central effects of $\mathrm{CRF}_{1}$ antagonism in IBS patients. Using an fMRI paradigm involving expectation of a painful electrical abdominal stimulus (Phelps et al., 2001; Naliboff et al., 2008; Kumari et al., 2009) to model abdominal pain-related anxiety in IBS patients and acute oral doses of a selective $\mathrm{CRF}_{1}$ antagonist, GW876008 (Di Fabio et al., 2008), this placebo (PLA)-controlled study aimed to address the following questions. (1) Does GW876008 attenuate the reactivity and effective connectivity of nodes within an emotional-arousal circuit, and is this effect greater in IBS patients? (2) Is the drug effect on this circuit moderated by anxiety? (3) Does GW876008 attenuate behavioral and neuroendocrine measures of anxiety and HPA axis activity differentially in patients compared with HCs?

\section{Materials and Methods}

Subjects. An age-matched sample of 31 right-handed females recruited from the greater Los Angeles community, 14 of which were diagnosed with IBS (mean age, $35.50 \pm 12.48$ years) and 17 non-IBS HCs (mean age, $33.65 \pm 15.87$ years), participated in this study. The University of California, Los Angeles (UCLA) Medical Institutional Review Board approved all procedures, and each subject provided informed consent. Diagnosis of IBS was guided by history and clinical examination, using the Rome II criteria (Thompson et al., 2000), and assessed by a gastroenterologist or nurse practitioner trained in the diagnosis of functional bowel disease. All bowel habit subtypes (constipation, diarrhea, and alternating) were deemed eligible to participate in this study. Of the 14 IBS patients, $43 \%$ were diagnosed with constipation-predominant symptoms, $21 \%$ with diarrhea predominance, and the remaining 36\% with alternating symptoms of constipation and/or diarrhea. Other eligibility criteria required that subjects tested negative for drugs of abuse in their urine, lacked any significant medical problems other than IBS, were free of past or present psychiatric illness as determined by the Mini International Neuropsychiatric Interview (Sheehan et al., 1998), and were not currently taking any medications with CNS effects. All subjects were tested in the follicular phase of their menstrual cycle defined as day 3-14 after menses.

Experimental design. This was a single center, randomized, doubleblind, PLA-controlled, three-period crossover study of two single oral doses $\left(20\right.$ or $200 \mathrm{mg}$ ) of the $\mathrm{CRF}_{1}$ antagonist GW876008 versus PLA. Study visits were conducted in the Center for Neurobiology of Stress Clinic and the Ahmanson-Lovelace Brain Mapping Center at UCLA. The study consisted of an initial screening visit (visit 1) and a familiarization visit (visit 2) wherein the subject was acclimated to the MRI environment (Fig. 1). During the familiarization visit, subjects with significant magnetic susceptibility-related artifacts were excluded. The familiarization visit was followed by three study treatment visits (visits 3-5), each separated by approximately 1 month (Fig. 1). At each treatment visit, a subject was randomized to one of the three treatment groups $90 \mathrm{~min}$ before the start of the study test session and then given a single oral dose of GW876008 (20 or $200 \mathrm{mg}$ ) or PLA. Immediately before drug or PLA administration, all subjects completed a series of questionnaires, including The Hospital Anxiety and Depression scale (Zigmond and Snaith, 1983), The Positive and Negative Affect Schedule (PANAS) subscales (Watson et al., 1988), and The State and Trait Anxiety Inventory (Spielberger, 1983). In addition, 90 min after drug or PLA treatment, subjects completed posttreatment measures of the PANAS and state anxiety subscales. Serial adrenocorticotropic hormone (ACTH) and cortisol blood samples were also collected before and after treatment at time points 0 , $0.5,1,1.5,2$, and $4 \mathrm{~h}$. Scanning commenced $120 \mathrm{~min}$ after administration of drug or PLA.

Drug, dosage, and administration. GW876008 (GlaxoSmithKline) is a highly selective and potent antagonist for the G-protein-coupled $\mathrm{CRF}_{1}$ receptor subtype (Di Fabio et al., 2008). Based on phase II clinical trials in patients with IBS, 20 and $200 \mathrm{mg}$ doses of GW876008 were chosen in an attempt to provide a sufficient therapeutic range (Dukes et al., 2009; Thoua et al., 2009). PLA tablets were identical to the active GW876008 tablets in all respects with the exception of omission of the active ingredient. Subjects were assigned to study treatment in accordance with the randomization schedule provided by GlaxoSmithKline. 
Table 1. Clinical characteristics

\begin{tabular}{|c|c|c|c|c|c|c|}
\hline & \multicolumn{2}{|c|}{ IBS patients } & \multicolumn{2}{|c|}{ Healthy controls } & \multicolumn{2}{|c|}{$\begin{array}{l}\text { Test statistics } \\
\text { and } p \text { values }\end{array}$} \\
\hline & Mean & SD & Mean & SD & $F$ & $p$ \\
\hline Age & 35.67 & 12.46 & 34.56 & 15.92 & 0.039 & 0.844 \\
\hline Current intensity & 4.50 & 1.65 & 4.50 & 2.55 & $<0.001$ & 1.000 \\
\hline Body mass index & 25.88 & 7.67 & 25.74 & 5.15 & 0.004 & 0.952 \\
\hline Unpleasantness ratings & 9.08 & 2.87 & 8.71 & 2.35 & 0.103 & 0.751 \\
\hline Intensity ratings & 11.58 & 2.50 & 11.94 & 3.15 & 0.136 & 0.715 \\
\hline State anxiety & 31.76 & 9.17 & 27.15 & 6.90 & 2.317 & 0.140 \\
\hline Trait anxiety & 35.33 & 7.95 & 27.34 & 8.28 & 6.432 & 0.018 \\
\hline
\end{tabular}

Means (SD) and one-way ANOVAs (Ftest statistics and $p$ values) for clinical characteristics in female IBS patients and healthy female controls.

Pain threshold assessment procedure. Delivery of transcutaneous electrical stimulation to the abdomen was accomplished using a Digitimer constant-current stimulator (model DS7A; Digitimer) and two electrode stimulation pads placed $6 \mathrm{~cm}$ apart over the subject's lower left abdomen in the region overlaying the sigmoid colon. Each stimulation to the abdomen consisted of a pulse train lasting $750 \mathrm{~ms}$ with a $2 \mathrm{~ms}$ pulse width and a frequency of $37 \mathrm{~Hz}$. For each subject, a moderately intense but not intolerable pain threshold (in milliamperes) was determined during study visit 2 (familiarization visit), and this level was then used on study treatment visits 3-5 (Fig. 1). Threshold assessment used a method of limits procedure beginning with a current intensity of $1.0 \mathrm{~mA}$, which was increased in $0.5 \mathrm{~mA}$ steps until the subject reported the stimulus was "aversive but tolerable." After a brief rest period, each subject was given an additional stimulation at this threshold level and asked to rate the level of pain intensity and unpleasantness on separate validated 20-point verbal descriptor anchored visual analog scales, with higher scores reflecting greater degrees of intensity and unpleasantness, respectively (Gracely et al., 1978) (Table 1).

Expectation of abdominal pain paradigm. To model the characteristic hypervigilance and symptom-related fear often reported by IBS patients, we used a paradigm of expected pain to the left lower abdomen, a region many IBS patients refer their pain to and which shows tenderness on physical exam. The threat of a pain experience in this body region would be expected to generate anticipatory anxiety and hypervigilance. Each subject was briefed on the experimental task immediately before the initiation of the experiment and then placed in the scanner bed in a supine position. Abdominal stimulation pads were attached, and the subject was fitted with a pair of goggles (Resonance Technology) that displayed the task stimuli using SuperLab Software (Cedrus). Before the start of the pain-expectation protocol, each subject underwent an emotional reactivity task wherein fMRI blood oxygen level-dependent (BOLD) responses were acquired while a subject matched and labeled negatively valenced emotions as well as identified the sex of human faces depicting angry or fearful expressions (data to be presented in a separate report). After completing the emotional reactivity task, a subject began the pain-expectation paradigm after a 3 min rest period.

The pain-expectation protocol consisted of two conditions; a Safe condition and a Threat condition (Fig. 1). In the Safe condition, subjects saw a blue circle indicating they would not receive stimulation to their abdomen. In the Threat condition, subjects viewed a red circle indicating they may receive a painful, but tolerable, stimulation to their abdomen at any time. For each trial, subjects also viewed a moving bar, incrementally filled with a gradient of color, indicating how much time was left in the current trial. For Threat trials, the color started as yellow and went to red as the trial proceeded in time, whereas for the Safe trials, the color started as purple and went to blue. Each subject received a total of seven Threat trials and six Safe trials per run, and each run was repeated twice (Run 1, Run 2). Each trial lasted $30 \mathrm{~s}$ with $15 \mathrm{~s}$ rest periods between trials. At the start and end of each run, subjects viewed a crosshair in the center of the screen for a $30 \mathrm{~s}$ period. Although subjects were instructed they could receive abdominal stimulation at any time during the Threat condition, in actuality abdominal stimulation was only delivered once per run, in the latter half of Run 1 and in the earlier half of Run 2. This experimental design was chosen to elicit the maximal arousal response based on previous research and extensive piloting (Naliboff et al., 2008).

fMRI acquisition and image processing. All brain imaging was conducted with a Siemens 3 Tesla Trio MRI scanner. For each subject, a high-resolution structural T2-weighted echo-planar imaging volume (spin echo; repetition time, $5000 \mathrm{~ms}$; echo time, $33 \mathrm{~ms}$; matrix size, $128 \times$ 128; 36 axial slices; field of view, $20 \mathrm{~cm}$; $3 \mathrm{~mm}$ thick, skip $1 \mathrm{~mm}$ ) was obtained coplanar with functional scans. Two functional BOLD runs were acquired (echo planar T2-weighted gradient echo; repetition time, $3000 \mathrm{~ms}$; echo time, $28 \mathrm{~ms}$; flip angle, $90^{\circ}$; matrix size, $64 \times 64$; 36 axial slices; field of view, $20 \mathrm{~cm} ; 3 \mathrm{~mm}$ thick, skip $1 \mathrm{~mm}$ ), each lasting $\sim 10 \mathrm{~min}$. A total of 432 BOLD volumes were collected during each functional run, and the first two images of each run were discarded to account for instability of signal in these early scans. In addition, threat trials that contained abdominal stimulation were also excluded for analysis purposes attributable to movement based artifacts. A high-resolution T1-weighted magnetization prepared rapid acquisition gradient echo MRI was acquired to aid in the registration of functional images and locate gross anatomical abnormalities.

All imaging analyses and summaries were generated using Statistical Parametric Mapping 5 (SPM5; Wellcome Trust Centre for the Study of Cognitive Neurology, London, UK) and Statistical Package for the Social Sciences (version 17) software. Images were converted from DICOM into NIFTI format, adjusted for slice timing, and realigned to control for superfluous motion. An average of the first 10 realigned fMRI images for each subject was coregistered with the subject's high-resolution echoplanar image and then transformed into standard Montreal Neurological Institute (MNI) stereotactic coordinates (resolution, $2 \mathrm{~mm}$ isotropic) and smoothed with an $8 \mathrm{~mm}$ isotropic Gaussian kernel.

Statistical analyses. A random-effects general linear model was used for statistical analyses of imaging data in SPM5. The primary analysis comprised linear contrasts between the $\mathrm{CRF}_{1}$ antagonist GW876008, at 20 and $200 \mathrm{mg}$ doses, versus PLA and subsequent alterations in BOLD signal for a priori defined regions of interest (ROIs) as measured by fMRI during the pain-expectation protocol in patients and HCs. Stimulus timings were convolved with the canonical hemodynamic response function provided in SPM5. Treatment effects of GW876008 at low $(20 \mathrm{mg})$ and high (200 mg) doses compared with PLA were examined within anatomically defined ROIs (left, L; right, R) for corticolimbic-pontine structures comprising an emotional-arousal circuit that included the AMYG, HPC, HT, INS, LCC, anterior cingulate cortical subregions [anterior midcingulate (aMCC) and subgenual (sgACC) anterior cingulate cortices], and OFC cortex (Valentino et al., 1999; Pezawas et al., 2005; Stein et al., 2007; Labus et al., 2008). Because of the small spatial extent and diffuse nature of brainstem nuclei that comprise the LCC, as well as the inherent limitations to spatial resolution of fMRI, we used binary template maps $( \pm 1$ SD) previously validated in vivo (Keren et al., 2009) in standard neuroimaging space (MNI) to anatomically identify ROIs for the left and right LCC (http://www.eckertlab.org/LC). Given the limiting spatial resolving power, the term LCC refers to the LCC region and not to any specific nucleus. Brain activity indexing expectation of pain for each ROI was defined by contrast beta images representing signal changes between experimental conditions (Threat - Safe). Because of the rapid activation of subcortical and brainstem regions (e.g., AMYG, LCC) during anticipatory pain, only the first $10 \mathrm{~s}$ of each trial was included in the analysis. Response to expectation of pain was then analyzed in a second level, 2 (group: IBS, HCs) $\times 3$ (treatment: PLA, 20 and $200 \mathrm{mg}$ doses of GW876008) general linear model, specifying subject as a random effect and controlling for order. For ROI analysis, activated and deactivated voxels were identified using an $\alpha$ level $<0.05$, corrected for multiple comparisons with false-discovery rate (FDR). Peak activity in representative voxels was extracted for secondary analyses of behavioral and neuroendocrine interactions and for effective connectivity modeling.

To explore the moderating effects of state and trait anxiety (pretreatment) on BOLD signal reductions by drug during expectation of abdominal pain in IBS and HCs, covariate analyses with a 2 (group: IBS, HCs) $\times$ 3 (treatment: PLA, 20 and $200 \mathrm{mg}$ of GW876008) repeated-measures general linear mixed-effects model were performed for LCC and HT activity. Moderator effects were examined graphically by displaying pa- 


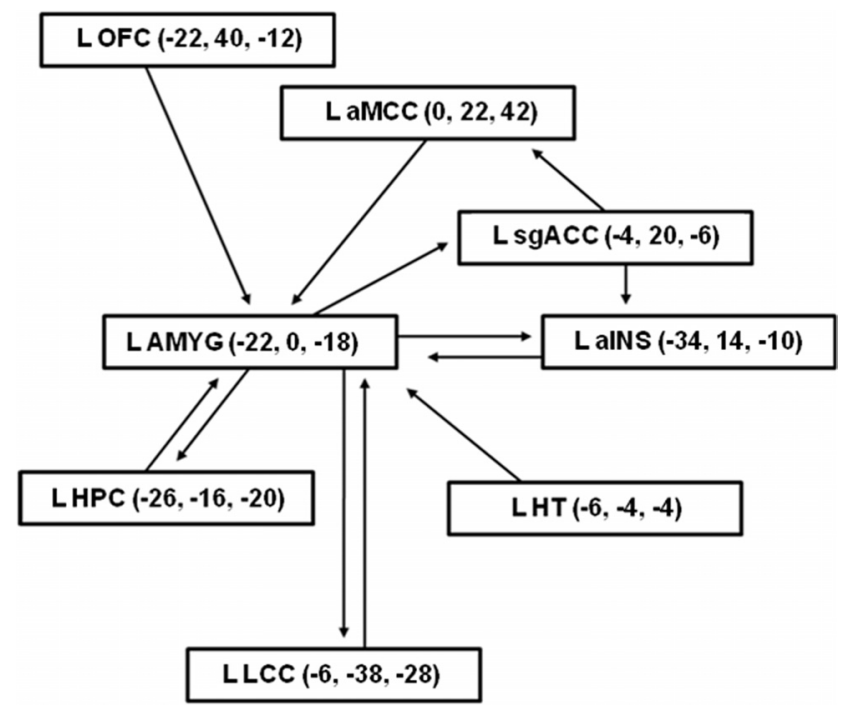

Figure 2. Path diagram from structural equation modeling analysis used for testing effective connectivity of network nodes of an emotional-arousal circuit involving left hemispheric structures. Nodes of the circuit are illustrated along with MNI coordinates $(x, y, z)$.

rameter estimates and 95\% normal confidence intervals for high (+1 SD above the mean), average (mean), and low ( $-1 \mathrm{SD}$ below the mean) values for anxiety (Holroyd et al., 2009).

In addition, we examined the effects of 20 and $200 \mathrm{mg}$ doses of GW876008 versus PLA on pretreatment and posttreatment measures of the PANAS and state anxiety subscales, as well as plasma cortisol and ACTH levels via repeated-measures general linear mixed-effects model. In each instance, specifying a heterogeneous autoregressive errorcovariance matrix structure yielded the best fit among the commonly used covariance structures as indicated by Akaike's information criteria.

Of the 31 subjects in our sample, three individuals were excluded from the analysis as a result of BOLD signal loss in ROIs across all three fMRI study treatment visits. Three additional subjects were removed from cortical and subcortical ROI analysis as a result of signal dropout during one of the three study treatment visits. However, these same subjects were included in the ROI analysis for the LCC because this region remained intact and unaffected by signal dropout. Presumably, signal dropout was caused by movement-related artifacts and/or air pockets trapped in the sinuses resulting in significant signal distortions (Buxton, 2002).

Effective connectivity analysis was applied to test the hypotheses that GW876008 would differentially alter the strength of connectivity within a stress-related emotional-arousal circuit in IBS and HCs during expectation of abdominal pain. The network of interest encompassed unilateral brain regions localized to the left hemisphere (Fig. 2), including the AMYG, HPC, HT, LCC, aMCC, sgACC, OFC, and ventral subregions of the anterior insula (aINS) (Pezawas et al., 2005; Stein et al., 2007; Labus et al., 2008). The spatial location of the voxels used to represent the regions or nodes of the circuit were selected from the primary SPM analyses. After specifying the structural model, path analysis using a structural equation modeling framework was performed with Amos 18.0 conducting full information likelihood estimation. SEs for parameter estimates were obtained via 200 bootstrapped samples and used to calculate 95\% confidence intervals for parameter estimates based on the normal distribution.

Residual variances, representing external input into the system (e.g., unspecified regions, psychological characteristics, hormonal milieu), were fixed at 35\% (McIntosh and Gonzalez-Lima, 1994) of the observed regional variances within group and treatment conditions. Drug treatment effects on the effective connectivity of the emotional-arousal network in IBS and HCs were tested using multigroup tests for invariance (Joreskog, 1971). Differences in the circuitry of the network were localized with pairwise comparisons between an unconstrained and partially constrained model using $\chi^{2}$ differences with 1 degree of freedom where a $\chi^{2}$ difference value of 3.84 represented $p<0.05$. The $200 \mathrm{mg}$ dose of GW876008 was chosen for the effective connectivity analysis based on results demonstrating no significant treatment differences for ROI activation after administration of GW876008 at low $(20 \mathrm{mg})$ versus high (200 mg) doses.

\section{Results \\ Clinical sample characteristics}

Table 1 provides the descriptive and inferential statistics for clinical characteristics of the two groups, assessed before randomization. Significant group differences for the dependent variables were only observed for the trait anxiety measure $\left(F_{(1,25)}=6.43\right.$, $p=0.018$ ). Before drug or PLA treatment, IBS patients had significantly higher levels of trait anxiety (mean \pm SD: IBS, $35.3 \pm$ 7.95; HC, $27.3 \pm 8.28$ ) but not state anxiety (mean \pm SD: IBS, $31.8 \pm 9.17 ; \mathrm{HC}, 27.1 \pm 6.90$ ) compared with HCs (Table 1).

\section{Effect of GW876008 on behavioral and neuroendocrine measures}

Analysis of the PANAS subscales (negative and positive effect, fear, hostility, and serenity) demonstrated no significant differences in mood attributable to drug treatment for either group. No significant drug effects were seen for pretreatment versus posttreatment state anxiety scores within or between groups. For ACTH pretreatment levels, there was a significant main effect for group $\left(F_{(1,100)}=4.48, p=0.037\right)$, with patients (mean $\pm \mathrm{SD}$ : $19.88 \pm 29.43 \mathrm{pg} / \mathrm{ml}$ ) showing overall lower ACTH levels across baseline compared with HCs (mean \pm SD: $102.31 \pm 25.48 \mathrm{pg} /$ $\mathrm{ml})$. In contrast, no significant group effect was found for plasma cortisol levels, nor did we find any significant treatment effects or group $\times$ treatment interactions for plasma cortisol or ACTH.

\section{Effects of GW876008 versus PLA on BOLD signal responses during expectation of abdominal pain \\ Main effects of treatment (PLA versus drug)}

Significant main effects for treatment (PLA, 20 and $200 \mathrm{mg}$ GW876008) were observed lateralized to the $\operatorname{Lg} \operatorname{sgCC}(F=14.24$, $p=0.02), \operatorname{L~OFC}(F=6.56, p=0.028)$, and L posterior INS $(F=$ 22.97, $p=0.038$ ), as well as bilaterally for the HPC (L: $F=16.89$, $p=0.036$; R: $F=20.13, p=0.006)$. Trends toward significant effects for treatment were also seen for the AMYG (L: $F=8.50$, $p=0.094 ; \mathrm{R}: F=10.65, p=0.084)$ and $\operatorname{RgACC}(F=13.32, p=$ $0.067)$. Planned contrasts revealed significant drug-induced reductions (20 and $200 \mathrm{mg}$ doses of GW876008 compared with PLA) in AMRI BOLD signal during pain expectation (Threat Safe) for the bilateral sgACC, as well as unilaterally for the AMYG, HPC, OFC, and posterior INS (all in L hemisphere; Table 2). Other ROIs, including the R AMYG and R HPC, showed significant attenuation in BOLD signal responses during pain expectation after administration of high $(200 \mathrm{mg})$ but not low (20 mg) doses of GW876008 compared with PLA (Table 2).

\section{Group $\times$ treatment interactions}

ROI analysis revealed significant group $\times$ treatment interactions for the L HT $(F=15.82, p=0.004)$ and L LCC $(F=6.88, p=0.043)$ during pain expectation. Significant group differences were found in response to administration of a $20 \mathrm{mg}$ [IBS(20 mg - PLA) - HC(20 $\mathrm{mg}$ - PLA)] or $200 \mathrm{mg}$ [IBS(200 mg - PLA) - HC(200 mg PLA)] dose of GW876008 relative to PLA for both the L HT and L LCC (Table 3). After PLA administration, patients showed significantly greater BOLD signal activity in the L HT $(t=6.06, p<0.001)$ and L LCC ( $t=3.37, p=0.002)$ during expectation of pain (Threat - Safe) compared with HCs, although this difference was not observed for drug treatment conditions (Figs. 3, 4). Patients 
Table 2. MNI coordinates for peak voxels showing significant treatment effects for each contrast (Threat $>$ Safe) across all subjects

\begin{tabular}{|c|c|c|c|c|c|c|}
\hline \multirow[b]{2}{*}{ Region } & & \multicolumn{2}{|c|}{ Voxels } & \multicolumn{3}{|c|}{$\begin{array}{l}\text { MNI coordinates } \\
(\mathrm{mm})\end{array}$} \\
\hline & & $t$ & $p$ & $x$ & $y$ & $z$ \\
\hline \multicolumn{7}{|c|}{ PLA > $20 \mathrm{mg}$ of GW876008 } \\
\hline \multirow[t]{2}{*}{ AMYG } & L & 3.03 & 0.045 & -26 & 2 & -22 \\
\hline & $R$ & 3.10 & 0.068 & 24 & -2 & -20 \\
\hline HPC & L & 3.27 & 0.053 & -32 & -14 & -14 \\
\hline INS & L & 4.88 & 0.011 & -42 & -28 & 14 \\
\hline \multirow[t]{2}{*}{$\operatorname{sgACC}$} & L & 3.31 & 0.015 & -2 & 20 & -6 \\
\hline & $R$ & 3.27 & 0.037 & 0 & 18 & -6 \\
\hline OFC & L & 1.94 & 0.044 & -22 & 38 & -12 \\
\hline \multicolumn{7}{|c|}{ PLA $>200 \mathrm{mg}$ of GW876008 } \\
\hline \multirow[t]{2}{*}{ AMYG } & L & 2.92 & 0.049 & -22 & 0 & -18 \\
\hline & $R$ & 3.26 & 0.046 & 24 & -2 & -22 \\
\hline \multirow[t]{2}{*}{ HPC } & L & 4.11 & 0.018 & -26 & -16 & -20 \\
\hline & $\mathrm{R}$ & 4.49 & 0.003 & 28 & -16 & -22 \\
\hline INS & L & 4.79 & 0.019 & -42 & -28 & 14 \\
\hline \multirow[t]{2}{*}{$\operatorname{sgACC}$} & L & 3.77 & 0.010 & -4 & 20 & -6 \\
\hline & $R$ & 3.65 & 0.034 & 0 & 18 & -6 \\
\hline OFC & L & 2.56 & 0.014 & -22 & 40 & -12 \\
\hline
\end{tabular}

MNI coordinates $(x, y, z), t$ test statistics, and $p$ values for each contrast of interest. FDR corrected, $p<0.05$.

Table 3. MNI coordinates for peak voxels showing significant group differences between treatment conditions for each contrast (Threat > Safe)

\begin{tabular}{|c|c|c|c|c|c|c|}
\hline & & \multicolumn{5}{|c|}{$\mathrm{IBS}>\mathrm{HCS}$} \\
\hline & & \multicolumn{2}{|c|}{ Voxels } & \multicolumn{3}{|c|}{$\begin{array}{l}\text { MNI coordinates } \\
(\mathrm{mm})\end{array}$} \\
\hline & & $t$ & $p$ & $x$ & $y$ & $z$ \\
\hline \multicolumn{7}{|c|}{ PLA $>20 \mathrm{mg}$ of GW876008 } \\
\hline HT & $\mathrm{L}$ & 4.19 & 0.002 & -4 & -4 & -6 \\
\hline $\mathrm{LCC}$ & L & 2.27 & 0.030 & -6 & -38 & -30 \\
\hline \multicolumn{7}{|c|}{ PLA $>200 \mathrm{mg}$ of GW876008 } \\
\hline HT & L & 3.98 & 0.002 & -6 & -4 & -4 \\
\hline LCC & $\mathrm{L}$ & 2.62 & 0.021 & -6 & -38 & -30 \\
\hline
\end{tabular}

MNI coordinates $(x, y, z), t$ test statistics, and $p$ values for each contrast of interest. FDR corrected, $p<0.05$.

showed significant BOLD signal reductions in the L HT after administration of the $20 \mathrm{mg}(t=4.02, p=0.003)$ and the $200 \mathrm{mg}$ dose $(t=$ $4.09, p=0.002)$ of GW876008 compared with PLA, whereas HCs showed no significant treatment effects (Fig. 3). Conversely, in the L LCC, HCs but not IBS patients showed significant increases in BOLD signal responses after treatment with either the $20 \mathrm{mg}(t=$ 2.41, $p=0.035)$ or the $200 \mathrm{mg}(t=2.86, p=0.018)$ dose of drug relative to PLA (Fig. 4).

Given the pretreatment group differences in trait anxiety (Table 1 ), we reexamined these differences using between-group contrasts for the L HT and L LCC while controlling for this variable using SPM5 $t$ tests specifying trait anxiety as a covariate of no interest at the second level. After inclusion of trait anxiety as a covariate into the model, significant group effects for the L LCC remained for both the $20 \mathrm{mg}(t=2.65, p=0.049)$ and the $200 \mathrm{mg}(t=2.44, p=0.027)$ doses of GW876008 compared with PLA. For the L HT, betweengroup contrasts remained significant at the low $(20 \mathrm{mg} ; t=3.08, p=$ $0.045)$ drug dose and approached significance at the high $(200 \mathrm{mg}$; $t=2.93, p=0.07$ ) drug dose relative to PLA treatment.

Effects of GW876008 versus PLA on network connectivity of an emotional-arousal circuit in IBS and HCs

As can be seen in Table 4, compared with PLA, administration of a $\mathrm{CRF}_{1}$ antagonist led to significant alterations in effective connectivity in the emotional-arousal circuit in IBS patients and
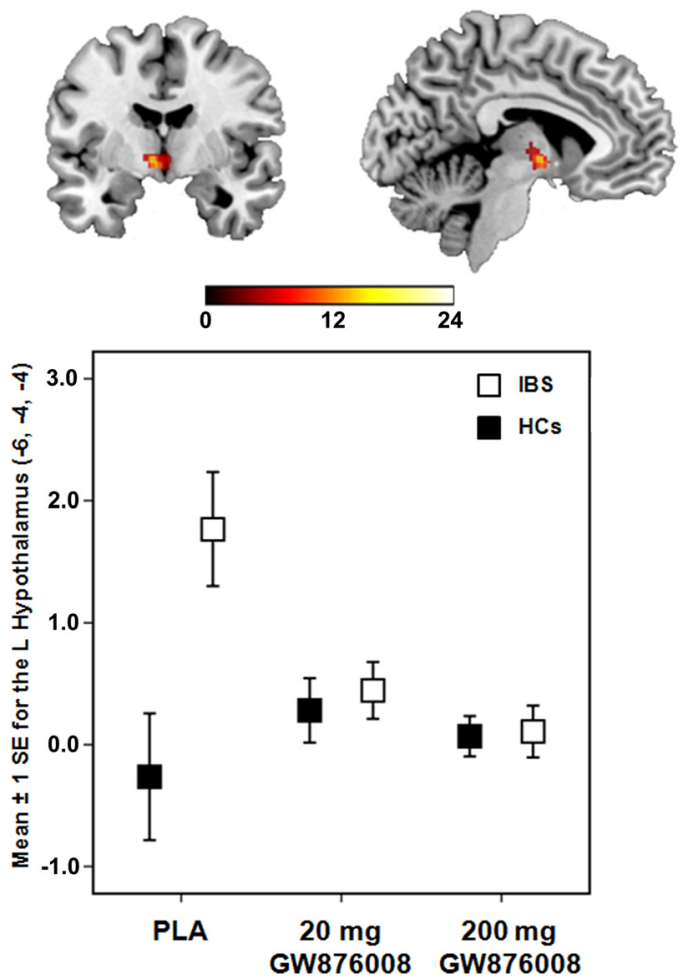

Figure 3. Error plot showing standard mean errors $( \pm 1 \mathrm{SE})$ for beta contrasts (Threat Safe) after PLA versus a 20 or $200 \mathrm{mg}$ dose of GW876008 for the $L$ hypothalamus in IBS patients and $\mathrm{HCs}$ during pain expectation.
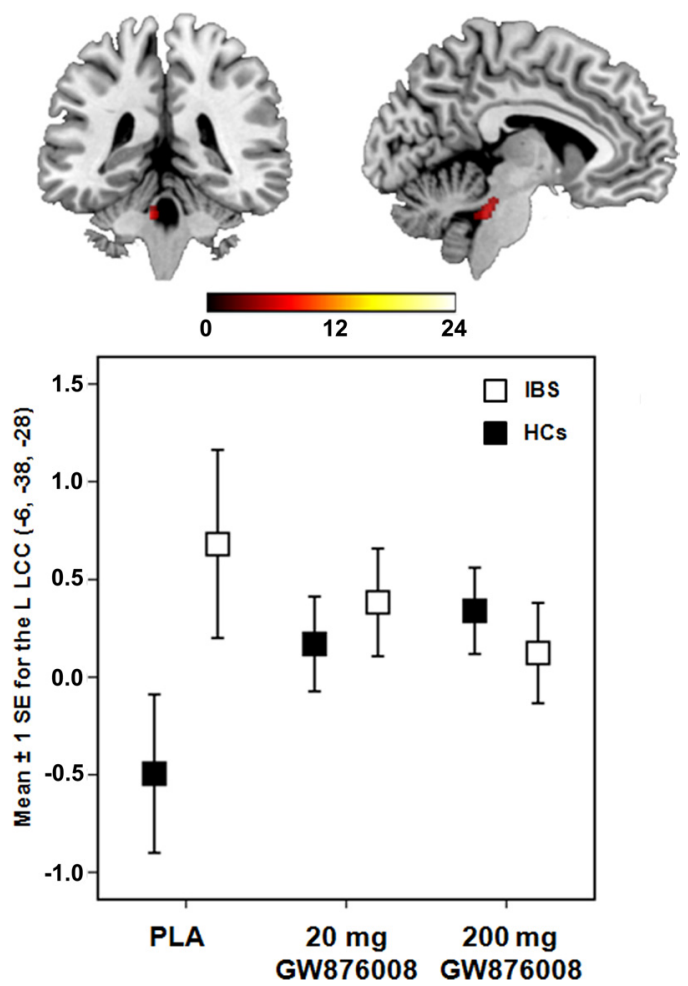

Figure 4. Error plot showing standard mean errors ( $\pm 1 \mathrm{SE}$ ) for beta contrasts (Threat Safe) after PLA versus a 20 or 200 mg dose of GW876008 for L LCC in IBS patients and HCs during pain expectation. 
HCs. Both patients and HCs showed drug-induced increases in positive effective connectivity for paths from ventral aINS to AMYG and greater negative connectivity between the sgACC and the aMCC. Although similarities in strength and direction of effective connectivity between hypothesized nodes of the emotional-arousal circuit were present for both groups for drug versus PLA treatment, the most dramatic changes in effective connectivity were observed in patients (Table 4; Fig. 5). Strikingly, in IBS patients, all paths to and from the AMYG showed dampening or qualitative changes in effective connectivity. For example, patients, but not HCs, showed significant drug-induced increases in positive effective connectivity for paths to the AMYG from OFC and HT, with levels approaching path estimates observed in HCs after PLA administration. Patients also showed significant drug-induced reductions in coupling between paths from aMCC and LCC to the AMYG, as well as from AMYG to HPC and ventral aINS. In HCs, only $50 \%$ of the AMYG afferents demonstrated drug-induced alterations in connectivity. Unlike the changes observed in IBS patients, the drug did not induce differences in connectivity in AMYG afferents to the HPC or aINS in HCs.

\section{Moderating effects of anxiety on GW876008 induced BOLD signal changes in hypothalamus and locus coeruleus complex during expectation of pain \\ Hypothalamus}

Baseline state anxiety (pretreatment) moderated the observed drug effects on the HT. No significant main effects for group $\left(F_{(1,22)}=1.86, p=0.186\right)$, treatment $\left(F_{(2,37)}=\right.$ $0.34, p=0.712)$, or state anxiety $\left(F_{(1,61)}=\right.$ $0.21, p=0.646)$ were found. Significant group $\times$ treatment $\left(F_{(2,37)}=9.64, p<\right.$ $0.001)$, group $\times$ state anxiety $\left(F_{(1,61)}=4.57\right.$, $p=0.037)$, and group $\times$ treatment $\times$ state anxiety $\left(F_{(2,39)}=6.36, p=0.004\right)$ interactions were observed for the L HT. At average and high levels of state anxiety, but not low levels of this construct, patients showed greater fMRI BOLD signal response activations in the L HT under PLA conditions compared with HCs (average: $t_{(40)}=3.63, p=0.001$; high: $\left.t_{(60)}=4.92, p<0.001\right)$. Additionally, patients at average and high levels of state anxiety showed greater reductions in BOLD signal responses for both $20 \mathrm{mg}$ (average: $t_{(41)}=2.06, p=0.046$; high: $t_{(61)}=3.30, p=0.002$ ) and $200 \mathrm{mg}$ (average: $t_{(37)}=2.17, p=$ 0.037 ; high: $\left.t_{(53)}=2.16, p=0.035\right)$ doses of drug compared with PLA.

\section{Locus coeruleus complex region}

For the L LCC region, no significant main effects or interactions for state anxiety were found, although a trend for a group $\times$ treatment interaction approached significance $\left(F_{(2,43)}=2.53\right.$, $p=0.091)$. Because of a priori hypotheses, we examined group $\times$ treatment effects on BOLD signal responses for the L LCC at low, average, and high levels of state anxiety in IBS and HCs. During PLA, patients showed significantly greater activation in the $\mathrm{L}$ LCC than HCs at both average $\left(t_{(60)}=2.52, p=0.015\right)$ and high $\left(t_{(66)}=2.72, p=0.008\right)$ levels of state anxiety but not low levels. At average and high levels of state anxiety, HCs, but not patients, showed drug-induced BOLD signal increases in the L sented by dark gray arrows.
Table 4. Path coefficients and $\chi^{2}$ differences for placebo versus GW876008 in IBS patients and healthy controls

\begin{tabular}{|c|c|c|c|c|c|c|}
\hline \multirow[b]{2}{*}{ Paths } & \multicolumn{3}{|l|}{ IBS patients } & \multicolumn{3}{|c|}{ Healthy controls } \\
\hline & $\begin{array}{l}\text { Placebo } \\
\text { Beta }\end{array}$ & $\begin{array}{l}200 \mathrm{mg} \text { of } \\
\text { GW876008 Beta }\end{array}$ & $\chi^{2} \Delta$ & $\begin{array}{l}\text { Placebo } \\
\text { Beta }\end{array}$ & $\begin{array}{l}200 \mathrm{mg} \text { of } \\
\text { GW876008 Beta }\end{array}$ & $\chi^{2} \Delta$ \\
\hline $\mathrm{AMYG} \rightarrow \operatorname{sgACC}$ & -0.284 & $0.604^{* *}$ & 9.5 & $0.654^{* *}$ & 0.255 & 4.5 \\
\hline AMYG $\rightarrow$ LCC & 0.118 & $-0.363^{* *}$ & 2.8 & -0.003 & 0.051 & 0.1 \\
\hline AMYG $\rightarrow$ HPC & $0.449^{* *}$ & -0.380 & 11.6 & 0.086 & 0.352 & 2.9 \\
\hline AMYG $\rightarrow$ alNS & $1.019^{* *}$ & $0.264^{* *}$ & 5.1 & -0.066 & -0.426 & 2.4 \\
\hline LCC $\rightarrow$ AMYG & $1.878^{* *}$ & -0.266 & 7.5 & -0.867 & 0.859 & 13.9 \\
\hline $\mathrm{HPC} \rightarrow$ AMYG & $-2.242^{*}$ & 0.161 & 8.0 & 0.190 & 0.254 & 0.0 \\
\hline alNS $\rightarrow$ AMYG & $-0.646^{* *}$ & 0.534 & 5.6 & -0.456 & 0.925 & 8.6 \\
\hline $\mathrm{aMCC} \rightarrow$ AMYG & $3.328^{* *}$ & 0.100 & 18.5 & -0.089 & -0.639 & 4.0 \\
\hline HT $\rightarrow$ AMYG & $-4.409^{* *}$ & 1.051 & 18.6 & 0.864 & 0.751 & 0.0 \\
\hline $\mathrm{OFC} \rightarrow$ AMYG & $-0.725^{* *}$ & $1.715^{* *}$ & 8.4 & -0.041 & -0.118 & 0.0 \\
\hline $\operatorname{sgACC} \rightarrow$ aMCC & $0.623^{* *}$ & $-0.759^{* *}$ & 18.1 & 0.245 & -0.288 & 5.2 \\
\hline sgACC $\rightarrow$ alNS & $-0.370^{* *}$ & $-0.718^{* *}$ & 1.0 & 0.197 & 0.247 & 0.0 \\
\hline
\end{tabular}

Critical values for the $\chi^{2}$ difference tests $\left(\chi^{2} \Delta\right)$ are 2.71, $p<0.10 ; 3.84, p<0.05 ; 6.64, p<0.01$; and 10.83, $p<$ 0.001 . Bold values indicate $\chi^{2}$ differences that reached significance. Significant beta path coefficients are designated by ${ }^{*} p<0.05$ and ${ }^{* *} p<0.01$.

Figure 5. Path coefficients for the effective connectivity analysis of an emotional-arousal circuit during expectation of abdominal pain after PLA versus high dose of the $\mathrm{CRF}_{1}$ antagonist ( $200 \mathrm{mg}$ of GW876008) in HCs and IBS patients. Parameter estimates that were significantly different are represented by green arrows, whereas those that were not significantly different are repre-

LCC. For example, at average levels of state anxiety, HCs showed significant signal increases after administration of a $20 \mathrm{mg}$ $\left(t_{(40)}=-2.01, p=0.052\right)$ dose of the antagonist compared with PLA treatment. At the $200 \mathrm{mg}$ dose, HCs showed significant increases in L LCC activation at both average and high levels of state anxiety (average: $t_{(68)}=-2.35, p=0.021$; high: $t_{(68)}=-2.28$, $p=0.026)$.

\section{Discussion}

Expectation of abdominal pain was associated with engagement of several cortical and limbic brain regions, a finding that parallels previous reports of somatic pain expectation (Phelps et al., 2001; Simpson et al., 2001; Straube et al., 2009). After acute administration of the $\mathrm{CRF}_{1}$ antagonist, patients with average and high state anxiety showed reductions in HT (but not LCC) activity, as well as a partial normalization of effective connectivity between key nodes of an emotional-arousal circuit, without detectable drug effects on HPA axis measures. The observed effects are consistent with a central role of $\mathrm{CRF} / \mathrm{CRF}_{1}$ signaling during pain expectation, as well as the hypothesized attenuating effects of $\mathrm{CRF}_{1}$ antagonism on regional activity and engagement of an emotional-arousal circuit in IBS patients. 
In contrast to an extensive animal literature showing anxiolytic effects of acutely administered $\mathrm{CRF}_{1}$ antagonists (Takahashi, 2001; Bale and Vale, 2004), acute administration of GW876008 in the current study had no significant effect on subjective measures of emotion, a finding compatible with results from clinical trials using the selective $\mathrm{CRF}_{1}$ antagonist pexacerfont (Sweetser et al., 2009; Coric et al., 2010). Moreover, similar to other reports on HPA axis alterations in stress-sensitive disorders, including IBS (Smith et al., 1989; Chang et al., 2009), patients showed significantly lower basal plasma ACTH, but not cortisol, levels compared with HCs. However, GW876008 administration did not affect plasma ACTH or cortisol levels. These data are consistent with findings from preclinical and early clinical studies demonstrating a lack of CRF receptor antagonist effects on HPA axis activity (Künzel et al., 2003; Sagami et al., 2004; Jutkiewicz et al., 2005).

Drug administration resulted in significant BOLD signal reductions within key regions of an emotional-arousal circuit during pain expectation in both patients and HCs. Significant BOLD signal reductions at both drug doses were observed in the AMYG, HPC, posterior INS, and OFC. These reductions were predominantly lateralized to the left hemisphere, although at high drug doses, significant BOLD signal reductions were also observed in the R AMYG and R HPC. These findings are in accord with immunohistochemical, in situ hybridization, and autoradiographical studies conducted in rats and nonhuman primates demonstrating the presence of $\mathrm{CRF}_{1}$ receptor mRNA and $\mathrm{CRF}_{1}$ binding sites within these regions and therefore fits well with the expected inhibitory effects of GW876008 (Millan et al., 1986; Radulovic et al., 1998; Sánchez et al., 1999; Chen et al., 2000).

The LCC supplies the major noradrenergic input to the forebrain and mediates emotional arousal, autonomic, and behavioral responses to stress and attention-related processes (Aston-Jones and Cohen, 2005). In preclinical studies, CRF has been shown to modulate LCC neuronal activity, and CRF-expressing neurons and $\mathrm{CRF}_{1}$ mRNA in the LCC have been identified (Valentino et al., 1983; Dautzenberg and Hauger, 2002). CRF-induced increases in tonic LCC neuronal discharge patterns and inhibition of LCC phasic responses to somatosensory and auditory stimuli (Valentino and Foote, 1987, 1988) is thought to facilitate the rapid disengagement from focused to labile attention (Aston-Jones and Cohen, 2005; Van Bockstaele et al., 2010). As expected, patients had greater threat-induced L LCC activation during PLA compared with HCs. In a previous study using a similar pain-expectation paradigm, Berman et al. (2008) reported greater activation of the dorsal brainstem region (including the LCC) in IBS patients, and this activation was correlated with state anxiety, as well as with the BOLD responses observed during aversive visceral distension. Surprisingly, we observed no drug effect on LCC activity in patients, whereas HCs showed an unexpected drug-induced increase in BOLD response, which may be attributable to the differential effects of GW876008 on the phasic and tonic discharge patterns of LCC neurons (Aston-Jones and Cohen, 2005) or to partial agonist effects of the antagonist (Schulz et al., 1996; Kosoyan et al., 2005).

Several possible explanations for the apparent lack of drug effect on LCC activity in patients should be considered, including species differences in the molecular characteristics and binding affinity of the $\mathrm{CRF}_{1}$ receptor in the LCC and $\mathrm{CRF}_{1}$ upregulation and/or sensitization in the LCC attributable to chronic stress exposure in IBS patients. However, activity did vary significantly during the PLA condition in IBS patients and GW876008 admin-
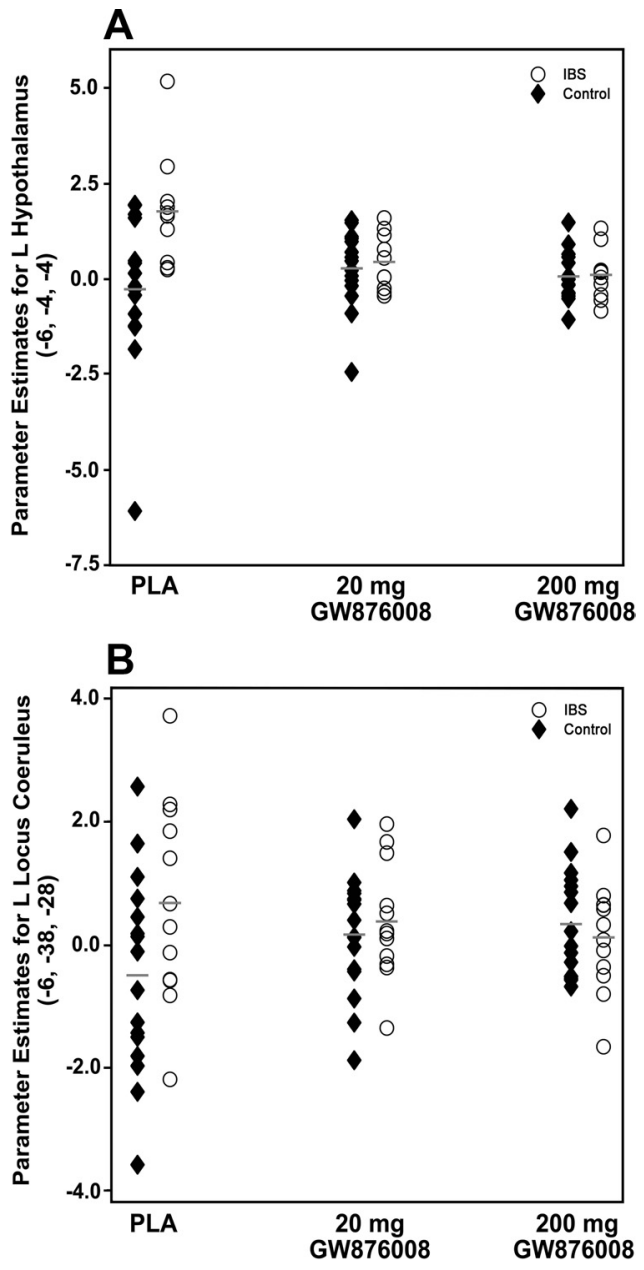

Figure 6. Scatter plots illustrating the distribution of parameter estimates for BOLD signal activity in the left hypothalamus $(\boldsymbol{A})$ and locus coeruleus complex $(\boldsymbol{B})$ in IBS patients and HCS across the three different treatment conditions (PLA, $20 \mathrm{mg}$ of GW876008, and $200 \mathrm{mg}$ of GW876008). Gray lines indicate parameter estimate means within group for each treatment condition.

istration did reduce this variability (Fig. 6), bringing levels of activation in the LCC to that seen in HCs.

The HT, via the HPA axis and the autonomic nervous system, plays a critical role in the neuroendocrine control of a variety of homeostatic functions, including the rapid and acute response to physiological and psychological stress. For example, stressinduced release of CRF from the paraventricular nucleus of the HT initiates the HPA axis response, an effect blocked by centrally administered $\mathrm{CRF}_{1}$ antagonists (Bale and Vale, 2004). Dysfunction in HPA axis regulation attributable to overactivation of CRF/ $\mathrm{CRF}_{1}$ signaling in response to chronic stress has been implicated in the pathophysiology of IBS symptoms (Chang et al., 2009). In the current study, patients showed significantly higher levels of trait anxiety than HCs, which is consistent with an upregulation of central stress and emotional-arousal in this population (Spiller et al., 2007; Rapps et al., 2008). Patients also showed significant BOLD increases in the L HT during pain expectation after PLA compared with HCs, whereas in response to antagonist administration at either dose, patients but not HCs showed significant BOLD decreases in the L HT. The former finding that IBS patients showed enhanced activity in the HT during pain expectation under PLA conditions compared with HCs suggests that central stress circuits may be upregulated in these patients. This 
finding is interesting in light of previous studies demonstrating morphological alterations in gray matter density in corticolimbic pain modulatory systems and in the HT in patients with chronic pain syndromes, including IBS (Schweinhardt et al., 2008; Blankstein et al., 2010; Seminowicz et al., 2010). It has been suggested that such structural changes may be attributable to usedependent hypertrophy, associated with upregulation of central stress response circuitry (Blankstein et al., 2010).

The inhibitory effects of GW876008 in the HT were moderated by the presence of average to high levels (but not low) of state anxiety in IBS patients; patients with average to high state anxiety showed greater BOLD responses in the L HT after PLA and greater BOLD signal reductions after drug than HCs. This finding parallels previous reports demonstrating that alterations in the central processing of visceral pain stimuli in IBS patients are moderated by anxiety symptoms (Elsenbruch et al., 2010a,b). Together, these findings support the hypothesis that the selective $\mathrm{CRF}_{1}$ antagonist GW876008 is capable of attenuating stressinduced hypothalamic activation during expectation of abdominal pain and that this effect is moderated, at least in part, by anxiety. The fact that patients were found to have lower plasma ACTH values before treatment and that no drug effect was observed on ACTH or cortisol levels suggests that GW876008 is not acting peripherally via the HPA axis but rather having central effects.

Under PLA conditions, IBS patients showed strong positive coupling between aMCC and AMYG, consistent with absence of negative feedback inhibition from the AMYG (Pezawas et al., 2005; Labus et al., 2008). Also, IBS patients showed strong coupling between other nodes of the emotional-arousal circuit (LCC and AMYG, AMYG and ventral aINS), whereas HCs showed weak negative coupling for these paths. Both groups showed similar drug-induced changes in connectivity (including the path from aINS to AMYG), although drug effects on connectivity were more prominent in IBS patients with path coefficients approaching those of HCs after drug compared with PLA. Thus, it appears that high doses of GW876008 may have partially normalized the effective connectivity of brain circuits involved in mediating arousal and stress-related emotional responses in patients compared with HCs.

Limitations of the current study include the small sample size of female patients. For example, sexual dimorphism of the LCC and sex-related differences in $\mathrm{CRF} / \mathrm{CRF}_{1}$ signaling have been reported recently (Bangasser et al., 2010a,b), and the majority of preclinical studies showing effectiveness of $\mathrm{CRF}_{1}$ antagonism were performed in male rodents. Furthermore, IBS refers to a heterogeneous group of patients, with differences in bowel habits, a history of stress sensitivity of symptoms, and comorbid conditions (Schmulson et al., 1999). These subgroups of patients may show differential responsiveness to a $\mathrm{CRF}_{1}$ antagonist. Finally, because of limitations in spatial resolution of fMRI, the identification of specific nuclei within the LCC region was not possible; therefore, we used previously published template maps to identify the LCC region (Keren et al., 2009).

\section{Summary and clinical implications}

This study provides the first evidence that acute oral dosing of GW876008 is sufficient to produce inhibitory effects on regional activity and connectivity within specific nodes of an emotionalarousal circuit in female IBS patients during pain expectation, confirming several hypotheses based on extensive preclinical data (Taché et al., 2009). However, early clinical trials with two different $\mathrm{CRF}_{1}$ receptor antagonists, GW876008 and pexacerfont, have not shown beneficial effects for IBS symptoms, although trends were observed in one study (Dukes et al., 2009; Sweetser et al., 2009; Thoua et al., 2009). The reason(s) for the apparent discrepancy between these findings and that of the current study, and the negative outcomes of several clinical trials, are unknown. However, it remains possible that these compounds only work in a subset of patients with clear stress sensitivity of their symptoms, high trait anxiety, and underlying hyperresponsiveness of stressrelated arousal circuits, including the HT.

\section{References}

Aguilera G, Millan MA, Hauger RL, Catt KJ (1987) Corticotropin-releasing factor receptors: distribution and regulation in brain, pituitary, and peripheral tissues. Ann NY Acad Sci 512:48-66.

Arborelius L, Owens MJ, Plotsky PM, Nemeroff CB (1999) The role of corticotropin-releasing factor in depression and anxiety disorders. J Endocrinol 160:1-12.

Aston-Jones G, Cohen JD (2005) An integrative theory of locus coeruleusnorepinephrine function: adaptive gain and optimal performance. Annu Rev Neurosci 28:403-450.

Bale TL, Vale WW (2004) CRF and CRF receptors: role in stress responsivity and other behaviors. Annu Rev Pharmacol Toxicol 44:525-557.

Bangasser DA, Curtis A, Reyes BAS, Bethea TT, Parastatidis I, Ischiropoulos H, Van Bockstaele EJ, Valentino RJ (2010a) Sex differences in corticotropin-releasing factor receptor signaling and trafficking: potential role in female vulnerability to stress-related psychopathology. Mol Psychiatry 15:877, 896-904.

Bangasser D, Zhang X, Valentino R (2010b) Sex differences in locus coeruleus dendritic morphology. Soc Neurosci Abstr 36:190.21.

Berman SM, Naliboff BD, Suyenobu B, Labus JS, Stains J, Ohning G, Kilpatrick L, Bueller JA, Ruby K, Jarcho J, Mayer EA (2008) Reduced brainstem inhibition during anticipated pelvic visceral pain correlates with enhanced brain response to the visceral stimulus in women with irritable bowel syndrome. J Neurosci 28:349-359.

Blankstein U, Chen J, Diamant NE, Davis KD (2010) Altered brain structure in irritable bowel syndrome: potential contributions of pre-existing and disease-driven factors. Gastroenterology 138:1783-1789.

Buxton RB (2002) Introduction to functional magnetic resonance imaging. Cambridge, UK: Cambridge UP.

Chang L, Sundaresh S, Elliott J, Anton PA, Baldi P, Licudine A, Mayer M, Vuong T, Hirano M, Naliboff BD, Ameen VZ, Mayer EA (2009) Dysregulation of the hypothalamic-pituitary-adrenal (HPA) axis in irritable bowel syndrome. Neurogastroenterol Motil 21:149-159.

Chen Y, Brunson KL, Müller MB, Cariaga W, Baram TZ (2000) Immunocytochemical distribution of corticotropin-releasing hormone receptor type-1 (CRF1)-like immunoreactivity in the mouse brain: light microscopy analysis using an antibody directed against the c-terminus. J Comp Neurol 420:305-323.

Coric V, Feldman HH, Oren DA, Shekhar A, Pultz J, Dockens RC, Wu X, Gentile KA, Huang SP, Emison E, Delmonte T, D’Souza BB, Zimbroff DL, Grebb JA, Goddard AW, Stock EG (2010) Multicenter, randomized, double-blind, active comparator and placebo-controlled trial of a corticotropin-releasing factor receptor-1 antagonist in generalized anxiety disorder. Depress Anxiety 27:417-425.

Dautzenberg FM, Hauger RL (2002) The CRF peptide family and their receptors: yet more partners discovered. Trends Pharmacol Sci 23:71-77.

Di Fabio R, St-Denis Y, Sabbatini FM, Andreotti D, Arban R, Bernasconi G, Braggio S, Blaney FE, Capelli AM, Castiglioni E, Di Modugno E, Donati D, Fazzolari E, Ratti E, Feriani A, Contini S, Gentile G, Ghirlanda D, Provera S, Marchioro C, et al. (2008) Synthesis and pharmacological characterization of novel druglike corticotropin-releasing factor 1 antagonists. J Med Chem 51:7370-7379.

Dukes GE, Mayer EA, Kelleher DL, Hicks KJ, Boardley RL, Alpers DH (2009) A randomised, double blind, placebo (PLA) controlled, crossover study to evaluate the efficacy and safety of the corticotrophin releasing factor 1 $\left(\mathrm{CRF}_{1}\right)$ receptor antagonist $(\mathrm{RA}) \mathrm{GW} 876008$ in irritable bowel syndrome (IBS) patients (Pts). Neurogastroenterol Motil 21:84.

Dunn AJ, Berridge CW (1990) Physiological and behavioral responses to corticotropin-releasing factor administration: is CRF a mediator of anxiety or stress responses? Brain Res Rev 15:71-100.

Elsenbruch S, Rosenberger C, Bingel U, Forsting M, Schedlowski M, Gizewski 
ER (2010a) Patients with irritable bowel syndrome have altered emotional modulation of neural responses to visceral stimuli. Gastroenterology 139:1310-1319.

Elsenbruch S, Rosenberger C, Enck P, Forsting M, Schedlowski M, Gizewski ER (2010b) Affective disturbances modulate the neural processing of visceral pain stimuli in irritable bowel syndrome: an fMRI study. Gut 59:489-495.

Fukudo S (2007) Role of corticotropin-releasing hormone in irritable bowel syndrome and intestinal inflammation. J Gastroenterol 42:48-51.

Fukudo S, Nomura T, Hongo M (1998) Impact of corticotropin-releasing hormone on gastrointestinal motility and adrenocorticotropic hormone in normal controls and patients with irritable bowel syndrome. Gut 42:845-849.

Gracely RH, McGrath F, Dubner R (1978) Ratio scales of sensory and affective verbal pain descriptors. Pain 5:5-18.

Holroyd KA, Labus JS, Carlson B (2009) Moderation and mediation in the psychological and drug treatment of chronic tension-type headache: the role of disorder severity and psychiatric comorbidity. Pain 143:213-222.

Joreskog KG (1971) Simultaneous factor analysis in several populations. Psychometrika 36:409-426.

Jutkiewicz EM, Wood SK, Houshyar H, Hsin LW, Rice KC, Woods JH (2005) The effects of CRF antagonists, antalarmin, CP154,526, LWH234, and R121919, in the forced swim test and on swim-induced increases in adrenocorticotropin in rats. Psychopharmacology 180:215-223.

Keren NI, Lozar CT, Harris KC, Morgan PS, Eckert MA (2009) In vivo mapping of the human locus coeruleus. Neuroimage 47:1261-1267.

Kosoyan HP, Grigoriadis DE, Taché Y (2005) The CRF1 receptor antagonist, NBI-35965, abolished the activation of locus coeruleus neurons induced by colorectal distension and intracisternal CRF in rats. Brain Res 1056:85-96.

Kumari V, Das M, Taylor PJ, Barkataki I, Andrew C, Sumich A, Williams SC, Ffytche DH (2009) Neural and behavioural responses to threat in men with a history of serious violence and schizophrenia or antisocial personality disorder. Schizophr Res 110:47-58.

Künzel HE, Zobel AW, Nickel T, Ackl N, Uhr M, Sonntag A, Ising M, Holsboer F (2003) Treatment of depression with the CRH-1-receptor antagonist R121919: endocrine changes and side effects. J Psychiatr Res 37:525-533.

Labus JS, Naliboff BN, Fallon J, Berman SM, Suyenobu B, Bueller JA, Mandelkern M, Mayer EA (2008) Sex differences in brain activity during aversive visceral stimulation and its expectation in patients with chronic abdominal pain: a network analysis. Neuroimage 41:1032-1043.

Lembo T, Plourde V, Shui Z, Fullerton S, Mertz H, Tache Y, Sytnik B, Munakata J, Mayer E (1996) Effects of the corticotropin-releasing factor (CRF) on rectal afferent nerves in humans. Neurogastroenterol Motil 8:9-18.

Longstreth GF, Thompson WG, Chey WD, Houghton LA, Mearin F, Spiller RC (2006) Functional bowel disorders. Gastroenterology 130:1480-1491.

Martinez V, Taché Y (2006) CRF1 receptors as a therapeutic target for irritable bowel syndrome. Curr Pharm Des 12:4071-4088.

Mayer EA (2000) The neurobiology of stress and gastrointestinal disease. Gut 47:861-869.

McIntosh AR, Gonzalez-Lima F (1994) Structural equation modeling and its application to network analysis in functional brain imaging. Hum Brain Mapping 2:2-22.

Millan MA, Jacobowitz DM, Hauger RL, Catt KJ, Aguilera G (1986) Distribution of corticotropin-releasing factor receptors in primate brain. Proc Natl Acad Sci U S A 83:1921-1925.

Million M, Grigoriadis DE, Sullivan S, Crowe PD, McRoberts JA, Zhou H, Saunders PR, Maillot C, Mayer EA, Taché Y (2003) A novel watersoluble selective $\mathrm{CRF}_{1}$ receptor antagonist, NBI 35965, blunts stressinduced visceral hyperalgesia and colonic motor function in rats. Brain Res 985:32-42.

Naliboff BD, Waters AM, Labus JS, Kilpatrick L, Craske MG, Chang L, Negoro H, Ibrahimovic H, Mayer EA, Ornitz E (2008) Increased acoustic startle responses in IBS patients during abdominal and nonabdominal threat. Psychosom Med 70:920-927.

Pezawas L, Meyer-Lindenberg A, Drabant EM, Verchinski BA, Munoz KE, Kolachana BS, Egan MF, Mattay VS, Hariri AR, Weinberger DR (2005) 5-HTTLPR polymorphism impacts human cingulate-amygdala interactions: a genetic susceptibility mechanism for depression. Nat Neurosci $8: 828-834$
Phelps EA, O’Connor KJ, Gatenby JC, Gore JC, Grillon C, Davis M (2001) Activation of the left amygdala to a cognitive representation of fear. Nat Neurosci 4:437-441.

Radulovic J, Sydow S, Spiess J (1998) Characterization of native corticotropinreleasing factor receptor type 1 (CRFR1) in the rat and mouse central nervous system. J Neurosci Res 54:507-521.

Rapps N, van Oudenhove L, Enck P, Aziz Q (2008) Brain imaging of visceral functions in healthy volunteers and IBS patients. J Psychosom Res 64:599-604.

Sagami Y, Shimada Y, Tayama J, Nomura T, Satake M, Endo Y, Shoji T, Karahashi K, Hongo M, Fukudo S (2004) Effect of a corticotropin releasing hormone receptor antagonist on colonic sensory and motor function in patients with irritable bowel syndrome. Gut 53:958-964.

Sánchez MM, Young LJ, Plotsky PM, Insel TR (1999) Autoradiographic and in situ hybridization localization of corticotropin-releasing factor 1 and 2 receptors in nonhuman primate brain. J Comp Neurol 408:365-377.

Schmulson M, Lee OY, Chang L, Naliboff B, Mayer EA (1999) Symptom differences in moderate to severe IBS patients based on predominant bowel habit. Am J Gastroenterol 94:2929-2935.

Schulz DW, Mansbach RS, Sprouse J, Braselton JP, Collins J, Corman M, Dunaiskis A, Faraci S, Schmidt AW, Seeger T, Seymour P, Tingley FD 3rd, Winston EN, Chen YL, Heym J (1996) CP-154,526: a potent and selective nonpeptide antagonist of corticotropin releasing factor receptors. Proc Natl Acad Sci U S A 93:10477-10482.

Schweinhardt P, Kuchinad A, Pukall CF, Bushnell MC (2008) Increased gray matter density in young women with chronic vulvar pain. Pain 140:411-419.

Seminowicz DA, Labus JS, Bueller JA, Tillisch K, Naliboff BD, Bushnell C, Mayer EA (2010) Regional gray matter density changes in brains of patients with irritable bowel syndrome. Gastroenterology 139:48-57.e2.

Sheehan DV, Lecrubier Y, Sheehan KH, Amorim P, Janavs J, Weiller E, Hergueta T, Baker R, Dunbar GC (1998) The Mini-International Neuropsychiatric Interview (M.I.N.I.): the development and validation of a structured diagnostic psychiatric interview for DSM-IV and ICD-10. J Clin Psychiatry 59:22-33.

Simpson JR Jr, Drevets WC, Snyder AZ, Gusnard DA, Raichle ME (2001) Emotion-induced changes in human medial prefrontal cortex. II. During anticipatory anxiety. Proc Natl Acad Sci U S A 98:688-693.

Smith MA, Davidson J, Ritchie JC, Kudler H, Lipper S, Chappell P, Nemeroff CB (1989) The corticotropin-releasing hormone test in patients with posttraumatic stress disorder. Biol Psychiatry 26:349-355.

Spielberger CD (1983) Manual for the State-Trait Anxiety Inventory (STAI). Palo Alto, CA: Consulting Psychologists Press.

Spiller R, Aziz Q, Creed F, Emmanuel A, Houghton L, Hungin P, Jones R, Kumar D, Rubin G, Trudgill N, Whorwell P (2007) Guidelines on the irritable bowel syndrome: mechanisms and practical management. Gut 56:1770-1798.

Stein JL, Wiedholz LM, Bassett DS, Weinberger DR, Zink CF, Mattay VS, Meyer-Lindenberg A (2007) A validated network of effective amygdala connectivity. Neuroimage 36:736-745.

Straube T, Schmidt S, Weiss T, Mentzel HJ, Miltner WH (2009) Dynamic activation of the anterior cingulate cortex during anticipatory anxiety. Neuroimage 44:975-981.

Sweetser S, Camilleri M, Linker Nord SJ, Burton DD, Castenada L, Croop R, Tong G, Dockens R, Zinsmeister AR (2009) Do corticotropin releasing factor-1 receptors influence colonic transit and bowel function in women with irritable bowel syndrome? Am J Physiol Gastrointest Liver Physiol 296:G1299-G1306.

Taché Y, Kiank C, Stengel A (2009) A role for corticotropin-releasing factor in functional gastrointestinal disorders. Curr Gastroenterol Rep 11:270-277.

Takahashi LK (2001) Role of $\mathrm{CRF}_{1}$ and $\mathrm{CRF}_{2}$ receptors in fear and anxiety. Neurosci Biobehav Rev 25:627-636.

Thompson WG, Longstreth GF, Drossman DA, Heaton KW, Irvine EJ, Müller-Lissner SA, Drossman DA, Corazziari E, Talley NJ, Thompson WG, Whitehead WE (2000) C. Functional bowel disorders and D. Functional abdominal pain. In: Rome II: the functional gastrointestinal disorders diagnosis, pathophysiology and treatment: a multinational consensus (Drossman DA, Corazziari E, Talley NJ, Thompson WG, Whitehead WE, eds), pp 351-432. McLean, VA: Degnon Associates.

Thoua NM, Hobson AR, Dukes GE, Kelleher D, Hicks K, Boardley R, Raeburn A, Emmanuel A (2009) The selective CRF-1 receptor antagonist GW876008 
attenuates stress induced rectal hypersensitivity in patients with irritable bowel syndrome (IBS). Neurogastroenterol Motil [Suppl] 21:85.

Trimble N, Johnson AC, Foster A, Greenwood-van Meerveld B (2007) Corticotropin-releasing factor receptor 1-deficient mice show decreased anxiety and colonic sensitivity. Neurogastroenterol Motil 19:754-760.

Vale W, Spiess J, Rivier C, Rivier J (1981) Characterization of a 41-residue ovine hypothalamic peptide that stimulates secretion of corticotropin and $\beta$-endorphin. Science 213:1394-1397.

Valentino RJ, Foote SL (1987) Corticotropin-releasing factor disrupts sensory responses of brain noradrenergic neurons. Neuroendocrinology $45: 28-36$

Valentino RJ, Foote SL (1988) Corticotropin-releasing hormone increases tonic but not sensory-evoked activity of noradrenergic locus coeruleus neurons in unanesthetized rats. J Neurosci 8:1016-1025.

Valentino RJ, Foote SL, Aston-Jones G (1983) Corticotropin-releasing fac- tor activates noradrenergic neurons of the locus coeruleus. Brain Res 270:363-367.

Valentino RJ, Miselis RR, Pavcovich LA (1999) Pontine regulation of pelvic viscera: Pharmacological target for pelvic visceral dysfunction. Trends Pharmacol Sci 20:253-260.

Van Bockstaele EJ, Reyes BA, Valentino RJ (2010) The locus coeruleus: a key nucleus where stress and opioids intersect to mediate vulnerability to opiate abuse. Brain Res 1314:162-174.

Watson D, Clark LA, Tellegen A (1988) Development and validation of brief measures of positive and negative affect: the PANAS scales. J Pers Soc Psychol 54:1063-1070.

Zigmond AS, Snaith RP (1983) The hospital anxiety and depression scale. Acta Psychiatr Scand 67:361-370.

Zorrilla EP, Koob GF (2010) Progress in corticotropin-releasing factor-1 antagonist development. Drug Discov Today 15:371-383. 